\title{
Prevalence of Sleep Problems and Its Relation to Sleeping Habits in Toddlers
}

\author{
Sima Maree ${ }^{1}$, Esa Mohammadi Zidi ${ }^{2}$, Saeed Yari ${ }^{3}$, Maryam Javadi ${ }^{1,4}$
}

${ }^{1}$ Children Growth Research Center, Qazvin University of Medical Sciences, Qazvin, Iran. ${ }^{2}$ Associate Professor (Ph.D. in health education\& promotion) Department of public health, School of Health, Qazvin University of Medical Sciences, Qazvin, Iran. ${ }^{3}$ Student Research Committee, (Department and Faculty of Health), Shahid Beheshti University of Medical Sciences, Tehran, Iran. ${ }^{4}$ Associate Professor (Ph.D. in Nutrition) Department of Nutrition, School of Health, Qazvin University of Medical Sciences, Qazvin, Iran.

\begin{abstract}
Background: Sleep problems in children have serious physical and psychological consequences such as obesity, aggression and attention deficit disorder in toddlers. The aim of the present study was to determine the prevalence of sleep problems and its relation with sleeping habits of toddlers in 2017. Methods: By random sampling from rural families of Razan city of Hamadan province, 120 mothers of 12- to 36-month-old children were selected and data collection tools included contextual questions, medical history and 33-question questionnaire of children's sleep habits (CSHQ) completed. Data were analyzed by SPSS software version 23, independent t-test, chi-square, Pearson correlation coefficient and multiple linear regression. Results: The mean age of the children was $22.82 \pm 7.53$ months and $55 \%$ of them were boys and the prevalence of sleep problems was $70.8 \%(95 \%$ confidence interval: 71.9-69.7). The average sleep duration of the children was 11 hours and more than $60 \%$ of the children went to bed after 23 o'clock. Results show that age is an important factor in most dimensions of CSHQ and age predicts daytime sleepiness $(\beta=-0.263)$, nocturnal wakefulness $(\beta=-0.113)$ and duration, Sleep time $(\beta=-0.108)$ and sleep resistance $(\beta=0.194)$ respectively. Also, parents' education and child's current weight were predictors of subscales of CSHQ questionnaire $(\mathrm{P}<0.05)$. In addition, there was a positive and significant correlation between sleep duration with infant sleep anxiety $(\mathrm{r}=0.527)$ and resistance to sleep $(\mathrm{r}=0.473)$ as well as nocturnal wakefulness with parasomnia $(r=0.416)(\mathrm{P}<0.001)$. Conclusion: Given the alarming prevalence of sleep problems in toddlers in the present study and the impact of some changeable factors on children's sleep health, designing interventions aimed at educating mothers to improve healthy sleep habits in toddlers is necessary.
\end{abstract}

Keywords: Sleep Habits- toddler- sleep problems- Parasomnia- night waking

Asian Pac J Environment and Cancer, 2 (1), 29-34

\section{Introduction}

Toddler needs good quality sleep for 11 to 13 hours a day for mental and physical development [1]. Younuch et al. (2016) study findings suggest that half of infants have poor sleep habits, 33\% have insufficient sleep and $12-10 \%$ have at least one of the sleeping or waking up problems. Also, $50 \%$ of children do not get enough sleep due to the need for parents to sleep (as the most common sleep problem) and $48 \%$ due to late sleep [2]. However, 81 to 100 percent of parents believed that their children had good sleep habits [2-3]. Information available about the prevalence of sleep problems and factors affecting
Submission Date: 03/09/2019 Acceptance Date: 05/02/2019

Corresponding Author:

Dr. Maryam Javadi

Children Growth Research Center, Qazvin University of Medical Sciences, Qazvin, Iran. Associate Professor (Ph.D. in Nutrition) Department of Nutrition, School of Health, Qazvin University of Medical Sciences, Qazvin, Iran.

Email:mjavadi@qums.ac.ir and mz_javadi46@yahoo.com 
awakenings, reduced daytime sleepiness) [9]. On the other hand, a number of studies have shown a strong positive relationship between sleep habits and stress [10-11]. Many studies have also suggested that stress itself is an environmental factor in cancer. Therefore, controlling the determinants of sleep habits from the perspective of cancer reduction is also important [12-16]. In previous studies, factors such as maternal education, maleness, low birth weight, presence of more than one older sibling, television viewing more than one hour in the evening, were associated with insomnia in toddlers [17]. An inverse relationship has been observed between toddler physical activity and infant night sleep [3]. Environmental factors such as ambient temperature [18-19], ventilation [20], ambient light [21], and infant nutritional behavior [22], also influence on the quality and quantity of children's sleep. The aim of this study was to determine the prevalence of sleep disorders and its related factors in a sample of toddlers.

\section{Materials and Methods}

The present study was a cross-sectional descriptive study that was carried out in the health centers of Razan city of Hamadan province from January 2016 to February 2016 with the aim of determining sleep problems and environmental, family and personal factors affecting sleep habits in 12-36-month-old children.

\section{Research community, samples and sampling process}

The study population was all mothers with 12 to 36 months old children in Razan city of Hamadan province. With the permission of the Deputy Health Directorate, a list of health homes in the city of Razan (including 72 centers) was prepared. Then, 12 health centers were selected by simple random sampling and 10 parents from each health home were coordinated to participate in the study. The sample size required for the present study was 96 persons based on Mohammadi et al study [23] with error of 0.05 and accuracy coefficient of 10 using the following sampling formula. Finally, 120 people were selected to participate in the study.

$$
n=\frac{\sigma^{2} Z_{1-\frac{\alpha}{2}}^{2}}{d^{2}}
$$

Inclusion criteria include: voluntary participation in study, literacy, child age between 12 and 36 months, child physical and mental health (child physical and mental health approval was performed by both health record and clinical examination by specialist physician), full residence in Razan, living with both parents at the same time and having a vaccination and supplementation program (Multivitamin or A + D and Iron) according to the national plan, lack of physical and mental disorders in the parents. Failure to participate in the study, diagnosis of acute or chronic diseases by a specialist physician, continuation of a child's medical treatment, physical presence of a parent, disability or parental drug, alcohol or psychiatric dependence, participants in the study were excluded.

\section{Data Collection tools}

Two questionnaires were used in the present study: a) Demographic information questionnaire which included 11 questions about age, sex, rating and birth weight of the child, age, education and job of parents and number of children. B) The 33-item Child Sleep Habits Questionnaire (CSHQ), which assesses sleep habits and screening for sleep problems in eight areas: 1) the child's resistance to going to bed, 2) sleep delay, 3) sleep adequacy, 4) sleep anxiety, 5) waking up at night, 6) parasomnia (sleeping problems such as walking, talking, nightmares, screaming, toothache, restlessness, etc.), 7) respiratory problems of sleeping 8) Daytime sleepiness [24]. The questions and items were scored on a three-point Likert scale (rarely (1 to 2 nights a week): one score, sometimes (3-4 nights a week): two points, often (5-7 nights a week): Three points). The validity and reliability of this tool have been demonstrated in other studies [25]. Falahzadeh and colleagues also confirmed the internal consistency and reliability of the questionnaire items by using Cronbach's alpha coefficient and test-test coefficient, respectively [26].

\section{The process of data collection}

The present study is part of a nutrition and children sleep thesis that approved by the Ethics Committee of Qazvin University of Medical Sciences (Ethics Code: IR.qums.REC.1396.347). After obtaining the consent of the Research Deputy of Qazvin University of Medical Sciences and the Deputy of Health of Hamadan University of Medical Sciences and coordination with the Behvarzes, mothers were invited to participate in the study by telephone. The mothers came to the health homes on their own suggested schedule. And the research team, while explaining the aims of the study, obtained consent from the mothers to participate in the study voluntarily. Oslo the research team, explaining how to answer questions, emphasized the confidentiality of the information and the anonymity of the questionnaires. Then, the mothers answered questions in the presence of the research team for approximately 25 to 30 minutes. The presence of the researcher was intended to ensure that mothers were fully and accurately answered and Eliminate their possible ambiguities about questions and items. After completing the questionnaires in order to observe the research ethics, a 120-minute educational program aimed at improving child sleep habits was delivered by the researcher. The pamphlet on sleeping child health and its effects on children's physical and mental health was delivered to mothers. The birth weight of the child and the term or preterm birth were extracted from the children's health record. The current weight of the children in the lowest clothing was measured using a Seca scale with accuracy of 50 grams.

\section{Data analysis}

After data entry in SPSS software version 23, data 
distribution was normalized using Kolmogorov-Smirnov test. and preliminary analysis was conducted to ensure that no violation of the assumption of normal, linearity and uniformity of dispersion. In addition to descriptive statistics and Chi-square test, independent t-test, multiple linear regression and Pearson correlation coefficient were used. Significance level was considered less than 0.05 in the present study.

\section{Results}

\section{Participant characteristics}

The mean age of the children in this study was $22.8 \pm 7.5$ months, also $55 \%$ (66 person) male, $25.8 \%$ (31 person) single child, 67\% (80 person) term and $84 \%$ (101 person) with a birth weight of 2500 grams or more. The mean current weight of the children was $12066 \pm 2113$ with a weight range of 18000 to $8700 \mathrm{~g}$. The mean age of mothers was $29.4 \pm 2.5$ years, $18.3 \%$ had university education and $11.7 \%$ were employed. The mean age of the fathers was $34.8 \pm 5.1$ years and $10.18 \%$ were college educated.

\section{Toddler sleep information}

The prevalence of sleep problems in toddlers is $70.8 \%$, according to mothers of the current study. $11 \%$ of children do not wake up at night, and $16 \%$ always wake up at night. $88 \%$ of children had daytime naps, $80 \%$ had resistance to sleep, and $60 \%$ had more than 20 minutes of late-night sleep. Toddlers' sleep duration on the 24-hour of holidays and non-holidays was no different, and it was 11 hours on average (8-15 hours). Also, more than 60 percent of children went to bed in the holidays and non-holidays after 23:00. The mean waking hours of the child on normal holidays were $8 \pm 1$ (12-6 AM) and 9 \pm 1 (6 AM to $13 \mathrm{PM})$, respectively, and the average daily nap duration was $105 \pm 58$ minutes. $10 \%$ of children had variable night sleep hours. The house of 10 percent of the participants had only one room, that with these exceptions, sleeping place of $87 \%$ of the children were in the parents' bedroom.

According to Table 1 (independent t-test results), there is a significant difference in the effect of age and gender of the child on the duration and hours of sleeping and waking on normal and holiday days.

Table 2 shows the correlation coefficients between the CSHQ subscales. As can be seen from the data in the table,

Table 1. Maternal Reports of Variables Related to Children's Sleep and Wake Hours by Age and Sex

\begin{tabular}{|c|c|c|c|c|}
\hline $\begin{array}{l}\text { Classification by age and sex of child } \\
\text { Children's sleep sizes }\end{array}$ & & $\begin{array}{c}\text { Age less than } 24 \text { months } \\
\text { Average (standard deviation) }\end{array}$ & $\begin{array}{c}\text { Age more than } 24 \text { months } \\
\text { Average (standard deviation) }\end{array}$ & P-value \\
\hline $\begin{array}{l}\text { The total duration of the child's sleep } \\
\text { in } 24 \text { hours of non-holidays (minute) }\end{array}$ & $\begin{array}{l}\text { Girl* } \\
\text { Boy** }\end{array}$ & $\begin{array}{l}717(93) \\
701(74)\end{array}$ & $\begin{array}{l}706(80) \\
704(73)\end{array}$ & 0.0007 \\
\hline $\begin{array}{l}\text { The total duration of the child's sleep } \\
\text { in } 24 \text { hours of holidays (minute) }\end{array}$ & $\begin{array}{l}\text { Girl } \\
\text { Boy }\end{array}$ & $\begin{array}{l}722(88) \\
687(93)\end{array}$ & $\begin{array}{l}725(101) \\
715(73)\end{array}$ & 0.0003 \\
\hline $\begin{array}{l}\text { Child's sleeping hours on non-holiday } \\
\text { nights }\end{array}$ & $\begin{array}{l}\text { Girl } \\
\text { Boy }\end{array}$ & $\begin{array}{c}22(1) \\
22(1.04)\end{array}$ & $\begin{array}{l}22(0) \\
23(0)\end{array}$ & 0.0001 \\
\hline $\begin{array}{l}\text { Child's sleeping hours on holiday } \\
\text { nights }\end{array}$ & $\begin{array}{l}\text { Girl } \\
\text { Boy }\end{array}$ & $\begin{array}{c}23(1) \\
23.5(1)\end{array}$ & $\begin{array}{l}23.05(1) \\
23.07(0)\end{array}$ & 0.0002 \\
\hline $\begin{array}{l}\text { Child's wake up in the morning on a } \\
\text { normal day }\end{array}$ & $\begin{array}{l}\text { Girl } \\
\text { Boy }\end{array}$ & $\begin{array}{c}9(1) \\
9.02(1)\end{array}$ & $\begin{array}{l}8(1) \\
8(0)\end{array}$ & 0.0002 \\
\hline $\begin{array}{l}\text { Child's wake up in the morning on a } \\
\text { holiday }\end{array}$ & $\begin{array}{l}\text { Girl } \\
\text { Boy }\end{array}$ & $\begin{array}{l}9(1) \\
9(1)\end{array}$ & $\begin{aligned} & 9(1) \\
8 & (1.024)\end{aligned}$ & 0.0004 \\
\hline
\end{tabular}

* Of the 54 girls in the study, 33 were younger than 24 months and 21 were older than 24 months; ** Of the 66 boys in the study, 39 were younger than 24 months and 27 were older than 24 months; $* * *$ Significant at $\mathrm{P}<0.001$.

Table 2. Pearson Correlation Coefficients between Subscales of the CSHQ Questionnaire in 120 Toddlers Participated in This Study

\begin{tabular}{|c|c|c|c|c|c|c|c|c|c|c|c|c|}
\hline & & 1 & 2 & 3 & 4 & 5 & 6 & 7 & 8 & 9 & 10 & 11 \\
\hline 1 & Resistance to sleep & - & & & & & & & & & & \\
\hline 2 & Delay in starting sleep & $0.266^{*}$ & - & & & & & & & & & \\
\hline 3 & Sleep duration & $0.473 * *$ & $0.213^{*}$ & - & & & & & & & & \\
\hline 4 & Sleep anxiety & $0.123^{*}$ & $0.057^{*}$ & $-0.527 * *$ & - & & & & & & & \\
\hline 5 & Night awakening & $0.344 * *$ & $0.153^{*}$ & $0.315^{* *}$ & $0.182^{*}$ & - & & & & & & \\
\hline 6 & Parasomnia & $0.253^{* *}$ & $0.108^{*}$ & $0.146^{*}$ & $0.163^{*}$ & $0.416^{* *}$ & - & & & & & \\
\hline 7 & Respiratory problems in sleep & $0.127 *$ & $0.093 *$ & $0.119^{*}$ & $0.109^{*}$ & $0.098 *$ & $0.233 * *$ & - & & & & \\
\hline 8 & Daytime sleepiness & $0.182 *$ & $0.138^{*}$ & $0.290 * *$ & $0.073^{*}$ & $0.265^{* *}$ & $0.147^{*}$ & $0.125^{*}$ & - & & & \\
\hline 9 & Sleeping place & $-0.471 * *$ & 0 & $0.087^{*}$ & $-0.08 *$ & $-0.062 *$ & 0 & 0 & 0 & - & & \\
\hline 10 & Night sleep time & 0 & $-0.037 *$ & 0 & $0.058^{*}$ & $-0.096^{*}$ & $0.079^{*}$ & $-0.013^{*}$ & 0 & 0 & - & \\
\hline 11 & Morning waking hours & $-0.058^{*}$ & $0.052 *$ & 0 & $-0.048 *$ & 0 & $-0.018 *$ & $-0.057 *$ & $0.07 *$ & 0 & $0.213^{*}$ & - \\
\hline
\end{tabular}

** Correlation is significant at the 0.01 level; Correlation is significant at the 0.05 level. 
Table 3. Standard and Non-standard Regression Coefficients Related to Demographic Variables and CSHQ Questionnaire Subscales

\begin{tabular}{lcccc}
\hline & independent variable & B & $\beta$ & P-value \\
\hline Resistance to sleep & Child's age & 0.183 & 0.194 & 0.013 \\
& Mother's education & 0.217 & 0.170 & 0.005 \\
Sleep duration & Child's current weight & -0.123 & -0.116 & 0.038 \\
& Child's age & -0.119 & -0.108 & 0.024 \\
Night waking & Child's age & -0.415 & -0.133 & 0.003 \\
& Father's education & 1.034 & 0.172 & 0.026 \\
Parasomnia & Boy sex & 0.642 & 0.216 & 0.007 \\
Respiratory problems in sleep & Child's current weight & 0.268 & 0.103 & 0.048 \\
Daytime sleepiness & Child's age & -0.811 & -.263 & 0.003 \\
& Child's current weight & -0.217 & -0.151 & 0.020 \\
The total score of the child's sleep habits & Mother's education & 2.213 & 0.253 & 0.003 \\
\hline
\end{tabular}

the strongest correlation coefficients were between sleep duration and sleep anxiety $(\mathrm{r}=-0.527)$, sleep duration and resistance to sleep $(r=0.473)$, sleep place and resistance to sleep $(\mathrm{r}=-0.471)(\mathrm{P}<0.001)$, respectively.

Table 3 presents standard and non-standard regression coefficients between demographic variables and CSHQ questionnaire subscales in toddlers participating in the study. Results show that age is an affecting factor in most dimensions of CSHQ and age predicts daytime sleepiness ( $\beta=-0.263)$, nocturnal wakefulness $(\beta=-0.113)$ sleep duration $(\beta=-0.108)$ and resistance to sleep $(\beta=$ $0.194)$, respectively. Also, parents' education and child's current weight were predictors of subscales of CSHQ questionnaire $(\mathrm{P}<0.05)$.

\section{Discussion}

The present study is the first study to determine the prevalence of sleep problems in toddlers in Iran and, the purpose of this study was to determine the relationship between sleeping habits and personal, environmental and family characteristics in toddlers in Razan, Hamadan province. The results of completing the CSHQ questionnaire indicated that sleep problems were present in $70.8 \%$ of the cases. The prevalence in Australia and the US is 55 to 60 percent [3-19-27], which can be due to cultural and social factors affecting one's sleep [28]. Similar to other studies, most of the children in the present study slept in their parents' bed [29-30], which had a significant positive relationship with sleep problems ( $\mathrm{r}$ $=0.02, \mathrm{P}<0.001)$. Because the presence of other people and their sleeping habits effect on the child's sleep [23]. Sleeping in children less than 5 years in a separate room is the strongest predictor of long-term sleep, which may be due to a decrease in wakefulness and increased child's Sleep Continuity [31]. Williams et al. also linked the place of sleep with toddler sleep problems and they suggest that the children sleep in the cradle until three years old and move to bed later. Because sleeping in a cradle is associated with an earlier bedtime, less sleep delay, less wakefulness, and an increase in toddler's nighttime sleep in compared to beds. In particular, this is significant in the child's resistance to sleep. In fact, shifting baby's sleep from cradle to bed has been associated with the prevalence and incidence of sleep problems in some toddlers [27]. Reference values of delayed sleep in children up to 6 years are 19 minutes on average [1]. The sleep latency in the present study is consistent with the results of Zhang et al. however, unlike the current study, it did not correlate with sleep problems in children [3]. Chang et al. Reported a negative correlation between sleep latency and sleep duration and daily nap time, which is in contradiction with the results of the present study [32]. Also, the inverse correlation of sleep duration with toddler age is similar to the results of other studies [29-33]. As expected, sleep duration will naturally decrease with age [8]. In the present study, sleeping and waking hours of children on normal days and holidays are later than the results of other studies [3-34]. Probably because of the absence of children participating in the present study in outdoor programs such as kindergarten that allow the child to sleep late at night and wake up late in the morning. Consistent with the study by Mindell et al., There was a greater variation in bedtime than wakefulness, and bedtime had a greater effect on the duration of a child's nighttime sleep [33]. In another study, the weekly program determines the child's bedtime, as they go to bed later in the weekend and wake up later [35]. This finding is consistent with the present study in that the mean sleep time of the child on normal and holidays is $22 \pm 1$ and $23 \pm 1$ (2-21 AM), respectively. In the present study, the most significant correlation was between the sleep anxiety of the child and the duration of sleep. Given the correlation between sleep anxiety with the duration of television viewing and the use of electronic media [36], seems to spending more time on television decrease the opportunity of child's sleeping and increase sleep anxiety [19]. The nocturnal awakening of children in the present study is similar to other studies [7-23]. The evolution of reducing nighttime awakenings is from birth to 3 years old and there is no difference between Asian and non-Asian children [37]. The frequency of wakefulness after birth is 0-3.4 times at night (1.7 times average), Which decreases with age, by the age of 2 , it reaches $0-2.5$ times at night $(0.7$ times 
average). Nighttime awakening and delayed sleep reduce sleep consistency and shorten sleep [1]. Breastfeeding is effective on the frequency of wakefulness so that breastfeeding is associated with increased wakefulness [38]. The correlations observed between child's nighttime wakefulness and daily nap time in the present study are similar to those of Cheung [32]. In the present study, respiratory problems in sleep have the highest correlation with parasomnia. Parasomnia itself resolves with age and remains a problem in only $4 \%$ of children [39]. The effects of increased air pollution and climate change on sleep have been associated with respiratory problems in sleep [40]. The daily nap rate of the children in this study is similar to other studies [3-29-30-34-41] and is in the desired range [1-8]. We didn't pay on the number of daily naps of children, rather we checked the duration of the daily nap, because according to a systematic review, the frequency of daily naps at 2 years old was $0.4-2.1$ (on average 1.2 times) and have biological root and did not differ across different communities [1].

In conclusion, this study was performed on Iranian children aged 3 to 6 years and sleep problems such as being late to bed, delayed sleep, and children's shared bedroom with parents were reported [42]. Probably, sleep problems started in toddlerhood and remained in pre-school years, because no corrective interventions have taken place. Regarding the prevalence of sleep problems of toddlers in Iranian society and the effect of sleeping habits, personal, environmental and family characteristics on it, designing interventions to control the factors that influence children's sleep habits appear useful.

\section{Weaknesses and strengths}

Conducting a descriptive study due to its inability to detect causal relationships, limiting the number of samples studied, limiting sampling location, and inability to extend its results to other communities, using self-report methods that associated with memory bias are the weaknesses of the present study. The strength of this study is the attention to toddler sleep problems, because even though the child has no sleep disorder, he or she cannot use his or her potential because of sleep problems.

\section{Recommendations}

Researching other economic and social communities, designing longitudinal and empirical studies, measuring child sleep habits using autographs instead of questionnaires for future studies is suggested.

\section{References}

1. Galland BC, Taylor BJ, Elder DE, Herbison P. Normal sleep patterns in infants and children: a systematic review of observational studies. Sleep medicine reviews. 2012;16(3):213-22.

2. Bonuck KA, Schwartz B, Schechter C. Sleep health literacy in head start families and staff: exploratory study of knowledge, motivation, and competencies to promote healthy sleep. Sleep health. 2016;2(1):19-24.

3. Zhang Z, Sousa-Sá E, Pereira J, Chaput J-P, Okely A, Feng X, et al. Correlates of nocturnal sleep duration, nocturnal sleep variability, and nocturnal sleep problems in toddlers: results from the GET UP! Study. Sleep medicine. 2019;53:124-32.

4. Becker SP, Sidol CA, Van Dyk TR, Epstein JN, Beebe DW. Intraindividual variability of sleep/wake patterns in relation to child and adolescent functioning: A systematic review. Sleep medicine reviews. 2017;34:94-121.

5. Byars KC, Yolton K, Rausch J, Lanphear B, Beebe DW. Prevalence, patterns, and persistence of sleep problems in the first 3 years of life. Pediatrics. 2012;129(2):e276-e84.

6. Wolfson AR, Montgomery-Downs H, Montgomery-Downs HE. The Oxford handbook of infant, child, and adolescent sleep and behavior: Oxford University Press; 2013.

7. Sun W, Li SX, Jiang Y, Xu X, Spruyt K, Zhu Q, et al. A community-based study of sleep and cognitive development in infants and toddlers. Journal of Clinical Sleep Medicine. 2018;14(06):977-84.

8. Bathory E, Tomopoulos S. Sleep regulation, physiology and development, sleep duration and patterns, and sleep hygiene in infants, toddlers, and preschool-age children. Current problems in pediatric and adolescent health care. 2017;47(2):29-42.

9. Buysse DJ. Sleep health: can we define it? Does it matter? Sleep. 2014;37(1):9-17.

10. Meltzer LJ, Mindell JA. Relationship between child sleep disturbances and maternal sleep, mood, and parenting stress: a pilot study. Journal of Family Psychology. 2007;21(1):67.

11. Sadeh A, Raviv A, Gruber R. Sleep patterns and sleep disruptions in school-age children. Developmental psychology. 2000;36(3):291.

12. Yari S, Akbari H, Gholami Fesharaki M, Khosravizadeh O, Ghasemi M, Barsam Y, et al. Developing a model for hospital inherent safety assessment: Conceptualization and validation. International Journal of Risk \& Safety in Medicine. 2018;29(3-4):163-74.

13. Yari S, Asadi AF, Nourmohammadi M. Occupational and Environmental Cancer. Asian Pacific Journal of Environment and Cancer. 2018;1(1).

14. Yari S, Asadi AF, Jarrahi AM, Nourmohammadi M. CARcinogen EXposure: CAREX. Asian Pacific Journal of Environment and Cancer. 2018;1(1).

15. Yari S, Naseri MH, Akbari H, Shahsavari S, Akbari H. Interaction of Safety Climate and Safety Culture: A Model for Cancer Treatment Centers. Asian Pacific Journal of Cancer Prevention. 2007;20(3):961-9.

16. Normohammadi M, Asadi AF. Job Stress and Safety Climate in Cancer Treatment Centers: Upgraded Model for Dimensions. Asian Pacific Journal of Environment and Cancer. 2018;1(2).

17. McDonald L, Wardle J, Llewellyn CH, van Jaarsveld CH, Fisher A. Predictors of shorter sleep in early childhood. Sleep medicine. 2014;15(5):536-40.

18. Lan L, Lian Z, Lin Y. Comfortably cool bedroom environment during the initial phase of the sleeping period delays the onset of sleep in summer. Building and Environment. 2016;103:36-43.

19. Richdale AL, Schreck KA. Sleep problems in autism spectrum disorders: prevalence, nature, \& possible biopsychosocial aetiologies. Sleep medicine reviews. 2009;13(6):403-11.

20. Strøm-Tejsen P, Zukowska D, Wargocki P, Wyon DP. The effects of bedroom air quality on sleep and next-day performance. Indoor Air. 2016;26(5):679-86.

21. Wilson KE, Miller AL, Lumeng JC, Chervin RD. Sleep environments and sleep durations in a sample of low-income preschool children. Journal of Clinical Sleep Medicine. 2014;10(03):299-305. 
22. Chaput J-P. Sleep patterns, diet quality and energy balance. Physiology \& behavior. 2014;134:86-91.

23. Mohammadi M, Ghalebaghi B, Bandi MG, Amintehrani E, Khodaie S, Shoaee S, et al. Sleep patterns and sleep problems among preschool and school-aged group children in a primary care setting. Iranian Journal of Pediatrics. 2007;17(3):213-21.

24. Molfese VJ, Rudasill KM, Prokasky A, Champagne C, Holmes M, Molfese DL, et al. Relations between toddler sleep characteristics, sleep problems, and temperament. Developmental neuropsychology. 2015;40(3):138-54.

25. Goodlin-Jones BL, Sitnick SL, Tang K, Liu J, Anders TF. The Children's Sleep Habits Questionnaire in toddlers and preschool children. Journal of Developmental \& Behavioral Pediatrics. 2008;29(2):82-8

26. Fallahzadeh H, Etesam F, Asgarian FS. Validity and reliability related to the Persian version of the Children's Sleep Habits Questionnaire. Sleep and Biological Rhythms. 2015;13(3):271-8.

27. Williamson AA, Leichman ES, Walters RM, Mindell JA. Caregiver-perceived sleep outcomes in toddlers sleeping in cribs versus beds. Sleep medicine. 2019;54:16-21.

28. Acebo C, Sadeh A, Seifer R, Tzischinsky O, Hafer A, Carskadon MA. Sleep/wake patterns derived from activity monitoring and maternal report for healthy 1-to 5-year-old children. Sleep. 2005;28(12):1568-77.

29. Ahn Y, Williamson AA, Seo H-J, Sadeh A, Mindell JA. Sleep patterns among south Korean infants and toddlers: global comparison. Journal of Korean medical science. 2016;31(2):261-9.

30. Hager ER, Calamaro CJ, Bentley LM, Hurley KM, Wang Y, Black MM. Nighttime sleep duration and sleep behaviors among toddlers from low-income families: associations with obesogenic behaviors and obesity and the role of parenting. Childhood obesity. 2016;12(5):392-400.

31. Sadeh A, Mindell JA, Luedtke K, Wiegand B. Sleep and sleep ecology in the first 3 years: a web-based study. Journal of sleep research. 2009;18(1):60-73.

32. Cheung CH, Bedford R, De Urabain IRS, Karmiloff-Smith A, Smith TJ. Daily touchscreen use in infants and toddlers is associated with reduced sleep and delayed sleep onset. Scientific reports. 2017;7:46104.

33. Mindell JA, Leichman ES, Composto J, Lee C, Bhullar B, Walters RM. Development of infant and toddler sleep patterns: real-world data from a mobile application. Journal of sleep research. 2016;25(5):508-16.

34. Plancoulaine S, Lioret S, Regnault N, Heude B, Charles MA, Group EMCCS. Gender-specific factors associated with shorter sleep duration at age 3 years. Journal of sleep research. 2015;24(6):610-20.

35. White KM, Terry DJ, Troup C, Rempel LA, Norman P, Mummery K, et al. An extended theory of planned behavior intervention for older adults with type 2 diabetes and cardiovascular disease. Journal of aging and physical activity. 2012;20(3):281-99.

36. Garrison MM, Liekweg K, Christakis DA. Media use and child sleep: the impact of content, timing, and environment. Pediatrics. 2011;128(1):29-35.

37. Mindell JA, Sadeh A, Wiegand B, How TH, Goh DY. Cross-cultural differences in infant and toddler sleep. Sleep medicine. 2010;11(3):274-80.

38. Mindell JA, Meltzer LJ, Carskadon MA, Chervin RD. Developmental aspects of sleep hygiene: findings from the 2004 National Sleep Foundation Sleep in America Poll. Sleep medicine. 2009;10(7):771-9.

39. Carter KA, Hathaway NE, Lettieri CF. Common sleep disorders in children. American family physician. 2014;89(5).

40. Tenero L, Piacentini G, Nosetti L, Gasperi E, Piazza M, Zaffanello M. Indoor/outdoor not-voluptuary-habit pollution and sleep-disordered breathing in children: a systematic review. Translational pediatrics. 2017;6(2):104.

41. Thorpe K, Staton S, Sawyer E, Pattinson C, Haden C, Smith S. Napping, development and health from 0 to 5 years: a systematic review. Archives of Disease in Childhood. 2015;100(7):615-22.

42. Javadi M, Javadi A, Kalantari N, Jaliloghadr S, Mohamad H. Sleep problems among pre-school children in Qazvin, Iran. The Malaysian journal of medical sciences: MJMS. 2014;21(6):52.

\section{(c) (1) (}

This work is licensed under a Creative Commons AttributionNon Commercial 4.0 International License. 